\title{
ФИЛОСОФИя
}

DOI: 10.17805/ggz.2018.1.7

\section{К вопросу о философии и практике менеджмента в сфере образования}

В. В. Гопко

Омский государственный педагогический университет

В течение последних двух десятилетий менеджмент в вузах странь стал одной из широко преподаваемых дисииплин. Возникает вопрос о возможности применения некоторых принципов менеджмента в условиях российской действительности. Несмотря на популярность и некоторую модность самого слова «менеджмент», последний, с точки зрения автора, не стал научной основой управления и не приобрел национальной специфики, которую можно было характеризовать как позитивную. В статье предпринимается попытка рассмотреть некоторые аспекты данного вопроса применительно к системе образования.

Ключевые слова: образование; российское образование; менеджмент; бюрократия; справедливость; культура; традици; необходимое условие развития; недостаточное условие развития

\section{The Issue of the Philosophy and Practice of Management in Education}

\author{
V. V. Gopko \\ Omsk State Pedagogical University
}

Within the last two decades management in higher educational institutions of Russia has become one of the widely taught disciplines. However, there is a question of the possibility of applying some principles of management in the conditions of the Russian reality. Despite the fact that the word "management" is popular and fashionable, management, in the author's opinion, has not become a scientific basis for governance and control and has not gained a national specificity which could be characterized as positive. In the article, the author makes an attempt to consider some aspects of this matter in relation to the system of higher education.

Keywords: education; Russian education; management; bureaucracy; justice; culture; traditions; necessary condition of development; insufficient condition of development 
Менеджмент - одно из понятий, ставших популярными в России в течение последних 15-20 лет. Само явление менеджмента в нашей стране не было абсолютно новым - система управления организациями и предприятиями существовала всегда, но их руководители просто не пользовались данным термином. И, напротив, в настоящее время менеджерами часто называют себя работники, к менеджменту не имеющие никакого отношения.

Вместе с тем, менеджмент - это наука, и наука специфическая. Она стремится к строгости и точности формулирования своих принципов, но имеет дело с крайне нестрогими и неточными объектами - человеком и созданными им организациями. Но менеджмент это и философия, основным содержанием которой является осмысление множества хронических проблем управления, связанных как с объектами, так и с субъектами управления. Качественное управление требует масштабности управляющей личности, вопервых, и присутствия чувства собственного достоинства в сознании управляемых, во-вторых.

Кроме того, очевиден факт заполнения значительной, а нередко и большей части жизни человека трудовой деятельностью. Где бы ни работал человек - в государственной или частной организации - он выступает или в роли управляющего, или в роли управляемого, или в обеих ролях одновременно.

Следовательно, менеджмент как наука и искусство управления является одним из важнейших факторов влияния на качество жизни (по крайней мере, весьма продолжительного ее отрезка) практически каждого человека.

Отмеченные факты позволяют рассматривать менеджмент как неотъемлемую и важную составляющую развития современной культуры. Для осуществления качественного менеджмента его носителям кроме соответствующих личностных качеств необходимо иметь соответствующее образование, так как менеджер должен уметь научно руководить организацией выдвигать гипотезы, проводить эксперименты, прогнозировать возможные проблемы и способы их преодоления и многое другое. Именно напряженная работа над созданием качественной теории менеджмента и не менее напряженная деятельность по внедрению данной теории в практику способствовала успешному развитию экономики США на рубеже XIX-XX вв. и в системе с прочими факторами обеспечила им выход в мировые лидеры.

В конечном итоге среди большинства ученых сложилось единое мнение о масштабах охвата менеджментом организаций, в которых осуществляются различные виды деятельности. Один из «отцов научного менеджмента» $\Phi$. Тейлор полагал, что менеджмент как форма руководства и управления должен присутствовать практически в любой организации, а также «что ос- 
новные принципы научной организации являются равно приложимыми ко всем видам человеческой деятельности» (Тейлор, 1991: 5).

Другой крупный теоретик и популяризатор менеджмента П. Друкер считал, что менеджмент - это самостоятельная научная дисциплина, которая призвана служить всем видам организаций, в каких бы сферах общества они ни функционировали. Он писал: «Когда впервые заговорили о менеджменте, этот термин означал “управление бизнесом", поскольку именно на крупномасштабных коммерческих предприятиях возникла необходимость в отдельном специализированном институте управления. Но во второй половине XX столетия стало понятно, что менеджмент является особым органом всех организаций без исключения. Ни одна организация не может обойтись без менеджмента, без управления - независимо от того, использует ли она этот термин. Все менеджеры занимаются, в принципе, одним и тем же, к какому бы типу их организация ни относилась» (Друкер, 2004: 372-373).

Последователь Ф. Тейлора М. Кук утверждал, что принципы менеджмента должны присутствовать во всех видах человеческой деятельности, включая и образование (Дункан, 1996: 39-40).

На теорию и практику менеджмента в самых различных сферах деятельности оказывают влияние традиции того или иного народа, политические системы и политические режимы, климат, географические масштабы страны и многое другое. Представляется достаточно интересным рассмотреть, соглашаясь с Тейлором, Друкером и Куком, каким образом в системе высшего образования нашей страны реализуются некоторые принципы научного менеджмента и реализуются ли они вообще. Кроме того, было бы интересно хотя бы приблизительно - затронуть некоторые особенности российского менеджмента как национального явления (национального не в этническом смысле, но в государственном).

Кроме деятелей, названных выше, принципы менеджмента разрабатывали многие теоретики и практики, стоявшие у его истоков. Во многом они (принципы) или сходны, или совпадают и нередко выглядят элементарными и очевидными. Вместе с тем российский и мировой опыт показывает, что простые и понятные принципы, призванные регулировать отношения между людьми, осуществить отнюдь не просто. Как представляется, один из таких принципов современного менеджмента заключается в утверждении, что если какой-либо деятельностью занимается коллектив (в особенности большой), то для высокой результативности его работы необходима слаженность, четкость и коллективная разработка принятия решений.

В связи со сказанным обозначим проблему так, как о ней говорил еще П. Друкер: «Мы постоянно говорим о “работе в команде”, — и все исследователи приходят к выводу о том, что работа высшего руководства возможна 
только на коллективной основе. А на практике мы наблюдаем - и не только в промышленности — “культ личности” высших должностных лиц в самых крайних его проявлениях» (Друкер, 2004: 104).

И первый вопрос, который напрашивается, едва мы окинем взглядом нашу систему высшего образования, можно сформулировать следующим образом: возможен ли качественный менеджмент в сфере высшего образования (если опять же признать, что качество менеджмента зависит от неукоснительного соблюдения его принципов, в том числе и принципа, изложенного выше) в условиях диктата министерств, опирающихся на «бумажную», но навязчивую волю бюрократизированного чиновничества?

Приходится констатировать, что в нашей стране вообще и в системе образования в частности «работа в команде» довольно часто подменяется работой по команде.

Речь идет о диктатуре Министерства образования и науки России, порождающей в ряде вузов диктатуру лиц, им назначенных.

Здесь мы вновь встречаемся с характерной для нашей страны информационной обертологической деятельностью, суть которой заключается в создании некой информационной обертки, которая призвана создавать видимость чего-либо (Гопко, 2010).

В течение продолжительного времени информационная обертка носит название «выборы ректора». Формально выборы действительно проводятся, но коллектив вуза может выбирать лишь из кандидатур, фактически утвержденных Минобрнауки. Если так, то главный менеджер любого вуза становится в достаточной степени вероятностной фигурой с точки зрения его управленческих возможностей. Если он удовлетворяет министерских чиновников по тем критериям, которые их интересуют, то остается широко открытым вопрос о том, способен ли он руководить коллективом вообще и большим коллективом в частности. И еще один вопрос: что делать с ним, если он в течение достаточно долгого времени демонстрирует лишь собственные амбиции?

Сложившаяся ситуация приводит к тому, что решения принимаются в верхней части пирамиды власти и продвигаются по нисходящей линии сверху вниз, от вышестоящих руководителей к нижестоящим. Таким образом, мы наблюдаем сугубо армейский способ осуществления как общего руководства, так и текущего управления вузами, что исключает результативное обсуждение профессорско-преподавательским составом реальных проблем, способное оказать влияние на принятие адекватных решений. Т. е. вузы переживают командную форму управления, что исключает позитивную самоорганизацию системы высшего образования на различных ее уровнях - 
начиная от названного выше министерства и заканчивая факультетами и кафедрами вузов.

Если же обратиться к такому «банальному» принципу менеджмента, как «справедливое отношение к персоналу» (Эмерсон, 1992: 44), то здесь бросается в глаза весьма существенный разлет в оплате труда руководства вузов и профессорско-преподавательского состава, что также является следствием авторитарной системы управления, которая, заботясь о самосохранении, делает ставку на удержание, если можно так выразиться, на своей стороне первых лиц организаций, путем выплаты им весьма высокого вознаграждения или разрешения присваивать им таковое самим себе. Это мгновенно привело к тому, что в «первые лица» нередко стали устремляться люди, которых волнует не результат деятельности организации ими руководимой, но возможность пополнять личный бюджет за счет данной организации.

Существенный ущерб отношению между руководителями и подчиненными в организациях (не только образовательных) наносит деформация системы ценностей, ставшая в 1990-е гг. результатом идолизации рынка как способа существования. В уставах коммерческих организаций в качестве основной цели записывается «максимизация прибыли», против чего протестовал П. Друкер: «Концепция максимизации прибыли на самом деле бессмысленна. Опасность этой концепции заключается в том, что она мифологизирует саму прибыльность коммерческого предприятия. <...> Прибыль - это не причина и не логическое обоснование экономического поведения и экономических решений, а скорее проверка их целесообразности и эффективности» (Друкер, 2004: 37-38).

Если врач лечит не для того, чтобы вылечить больного, но для того, чтобы получить прибыль, то выздоровление больного утрачивает свою значимость. Что касается вузов как некоммерческих организаций, то борьба за прибыль, хотя ее формально и не существует, привела к резкому снижению требовательности к студентам, обучающимся на внебюджетной основе, поскольку вносимая ими плата за обучение обеспечивает выживание вузов, что, в свою очередь, породило обвал качества знаний обучающихся.

Есть профессии, требующие от работника знаний и таланта, успешно сочетающиеся с инновационной деятельностью и, более того, предполагающие ее, но совершенно несовместимые с производством прибыли. К таковым, безусловно, относятся многие профессии гуманитарной сферы, включая профессии педагога и ученого. Не следует путать прибыль и достойную зарплату, которую должно гарантировать государство, чтобы исключить заботу педагога и ученого о производстве прибыли. Педагоги и ученые должны иметь сознание, свободное от бремени борьбы за выживание, но направленное на научное постижение истины и на воспитание молодого поколения. Но 
данные утверждения настолько тривиальны, насколько, к сожалению, и неосуществимы.

И еще об одном принципе менеджмента. Г. Эмерсон одним из принципов управления любой организацией называл среди прочего здравый смысл, имея в виду необходимость учета влияния тех или иных решений на производственный процесс не только в настоящем, но и в будущем. Он писал: «Вместо того, чтобы правильно пользоваться тем, что есть, мы приобретаем лишние вещи. В этом сказывается все то же наше национальное нежелание работать головой и мускулами» (Эмерсон, 1992: 26).

Это строки, адресованные американским предприятиям, приобретавшим избыточное оборудование и технику, Г. Эмерсон опубликовал в 1911 г., но их вполне можно адресовать некоторым современным российским управленцам - бизнесменам от высшего образования. Трудно будет найти в истории страны более нелепую и вредную реформу высшего образования, которую наша образовательная власть «приобрела» в странах Европы. Речь идет о рассечение высшего российского образования на бакалавриат и магистратуpy.

Бакалавриат за рубежом - это что-то вроде нашего среднего профессионального образования, которое студенты получают в техникумах и колледжах. Что касается высшего образования, то оно, несмотря на известные недостатки, в нашей стране до последнего времени было организовано значительно рациональнее западного, поскольку отличалось четкой специализацией и достаточно широкой теоретической и общекультурной подготовкой, что отнюдь не препятствовало переучиванию, переподготовке и любому послевузовскому образованию.

Современная эпоха - это эпоха образовательной трансдисциплинарности, о чем в последнее время стало модно говорить, но она (эпоха) продолжает оставаться временем глубокого, филигранного профессионализма и, следовательно, обстоятельной специализации. Безусловно, подготовка специалиста в российских вузах соответствовала требованию времени, опережая в этом страны Запада. Ни бакалавр, ни магистр, у которых в дипломах фиксируется так называемое направление подготовки, не могут сравниться со специалистом. И никакие компетенции, даже если их количество довести в так называемых стандартах каких угодно поколений до совершенно безумного количества, не могут заменить собой понятных, строгих и реализуемых знаний, умений и навыков.

Можно возразить: но современная эпоха - это эпоха не только и не столько специализации, но и эпоха, требующая от работника готовности к деятельности в самых различных профессиональных сферах, и, таким образом, бакалавриат, дающий лишь «направление» образованию, позволит его, 
работника, быстро и эффективно переучить в рамках этого «направления». Но представляется, что действующий специалист, твердо овладевая какойлибо профессиональной квалификацией, постоянно готов к переучиванию и расширению своих знаний и умений. Более основательная и более глубокая подготовка специалиста (и, следовательно, более развитое его профессиональное сознание) позволяют ему успешно адаптироваться к новым жизненным условиям и новым профессиональным требованиям. Кроме того, представляется, что переучивать недоученного значительно сложнее, чем ученого.

Значимость любой реформы в сфере высшего образования определить достаточно просто: она может считаться результативной и, следовательно, иметь смысл только в том случае, когда она оказывает прямое влияние на студента и приводит к улучшению качества его обучения. Если же реформа лишь увеличивает нагрузку на преподавателей, заставляя их терять время и силы на составление никому не нужных бумаг или их электронных близнецов, и на студента никакого позитивного влияния не оказывает, то она вредна, да и реформой не является.

Речь идет, среди прочего, и о стратегическом менеджменте, который осуществляет Минобрнауки, дробя высшее образование и активно имитируя реформу. Но это, так сказать, промежуточный итог. Следующим итогом, видимо, будет острая нужда страны в гастарбайтерах с высшим образованием, которых придется, надо полагать, импортировать из Китая, Южной Кореи или еще откуда-нибудь. Там, правда, тоже бакалавры и магистры, но они, по сути, гораздо ближе с точки зрения качества квалификации к нашим, теперь уже, практически, бывшим, специалистам.

Узкая профессиональная специализация и широкая общекультурная и теоретическая подготовка (позволяющая в любой момент расширить названную специализацию) - вот требование времени. Специализация у нас размыта, а общекультурная подготовка, которая в нашей стране начиналась еще в школе, сужена до абсурда.

Таким образом, в сфере высшего образования мы имеем не научный менеджмент, но обычный российский чиновничий бюрократизм. Бюрократизм характеризуется избыточным количеством функционеров, он порождает своего рода квазиполитическую богему, которая, в свою очередь, порождает избыточное количество команд, проверок и отчетов, заставляя реальных работников совершать бессмысленные траты энергии. Вокруг системы образования наблюдается некая суета, которая имитирует реформы. Все это приводит к появлению в организации наростов, паразитирующих на ней и производящих абсурдные, контрлогичные действия, препятствующие успешному, результативному функционированию организации. Возникает эффект само- 
торможения системы, приводящий ее к разложению. Последнее может длиться достаточно долго, если организация выполняет все же некоторую в целом необходимую обществу работу, хотя и с низким коэффициентом полезного действия.

Говоря о проблемах высшей школы, нельзя не затронуть и школу среднюю, поскольку она - основной поставщик студентов для вузов. Острой проблемой стало ее кадровое обеспечение, поскольку многие выпускники педагогических вузов работать школьными педагогами не хотят, что порождает абсолютно абсурдную ситуацию: нехватку учителей при избытке их производства.

Отталкиваясь от положений модальной логики, следует отметить, что существуют факторы, которые являются абсолютно необходимыми, хотя и не достаточными для зарождения и развития как самой жизни, так и различных ее проявлений. Кислород, вода, продукты питания и многое другое необходимы для жизни человека и других животных и являются — каждый элемент в отдельности - необходимым, но не достаточным фактором существования и развития названных существ. Если обратиться к тем или иным явлениям культуры, то совершенно очевидно, что для того, чтобы вырастить успешную команду хоккеистов, нужен лед, который является необходимым, но недостаточным условием существования и развития этого вида спорта; без наличия воды нельзя воспитать пловца; для успешного ведения современной войны необходим комплекс факторов - успешная разведка, обученный личный состав вооруженных сил, талантливое командование и многое другое, но без новейшего оружия все это не приведет к победе над противником.

Таким образом, необходимое, но недостаточное условие развития (ННУР) - это фактор, без которого формирование, функционирование и максимально возможная эффективность различных форм человеческой деятельности и систем, созданных человеком, не может осуществляться.

Характерный образец поиска и определения необходимого, но недостаточного условия развития можно теоретически продемонстрировать с помощью системы образования в Российской Федерации, включая школьное. Нет необходимости доказывать, что в обществе знаний важную роль призваны играть работники знаний. Следовательно, необходимо, чтобы талантливая и энергичная молодежь обоих полов стремилась к соответствующим профессиям. Но подобного стремления не произойдет, если представители данных профессий будут чувствовать себя изгоями общества, в котором: 1) бурно развивается процесс автомобилизации; 2) требуются немалые средства для приобретения современного жилья; 3) необходимы значительные средства для качественного отдыха и весьма значительные - для следования моде и современному образу жизни в целом, что весьма важно для молодых людей. 
Если в условиях социализма власть могла призывать педагогов к подвижничеству, что вполне соответствовало пафосной мифологичности коммунистической идеологии, то в условиях рационального рынка (нередко не столько рационального, сколько циничного) показателем общественной оценки работника и показателем его личной успешности является уровень дохода, исключающий принадлежность работника знаний к категориям «беднота», «малоимущие» и т. п.

Заменить же необходимую и достаточно высокую доходность работникам знаний научным и педагогическим творчеством, способным компенсировать отсутствие названной доходности, невозможно, поскольку, во-первых, нищета и творчество в современных условиях плохо совместимы, и, вовторых, творческий потенциал интеллектуалов, помимо названной выше «рыночной» причины, подавляется неумелым управлением власти системой образования, которое (управление) выражается в навязывании западных образцов, причем сугубо в «бумаготворческом» варианте.

Таким образом, с достаточной долей уверенности можно утверждать, что без высокой и регулярно индексируемой заработной платы современного учителя проблемы образования решены не будут ни в ближайшем обозримом, ни в дальнейшем необозримом будущем. Безусловно, данный фактор высокая зарплата педагогов - является необходимым, но недостаточным условием развития системы образования как школьного, так и высшего.

Названную проблему (проблему определения и реализации ННУР) можно рассматривать в рамках теорий сложных систем, и в этом случае ННУР будет выступать как важнейший фактор максимально возможного развития системы. Если, рассматривая систему образования, обратиться к сетевой концепции М. Кастельса (Кастельс, 2000), то высокую оплату труда педагогов можно рассматривать как узел сети, с которым так или иначе связаны все узлы феномена, и узел, без которого исчезает значительная часть самой сети или же последняя становится нефункциональной.

Когда некоторые чиновники не знают, что делать для реального развития системы образования, и тем более когда они не желают что-либо делать, они говорят об «объективных причинах», которые (причины) не позволяют им совершать продуктивные действия. Но этими «объективными причинами» нередко являются решения и приказы вышестоящих организаций. Озадачивает то, что в условиях диктатуры Минобрнауки изменить что-либо крайне сложно, даже если Министерство возглавляет талантливый и понимающий руководитель, так как оно (Минобрнауки) встроено в вертикаль власти.

Остается лишь одно: делать свое дело, стараясь по возможности минимизировать влияние Минобрнауки в его негативной части на качество препо- 
давания в вузах и школах всех изучаемых студентами и школьниками дисциплин, в том числе и такой важной дисциплины, каковой является менеджмент, с надеждой на то, что настоящие менеджеры когда-нибудь займут должности в названном министерстве.

\section{СПИСОК ЛИТЕРАТУРЫ}

Гопко, В. В. (2010) Примитив и обертология [Электронный ресурс] // Информационный гуманитарный портала «Знание. Понимание. Умение». № 1 - Философия. Политология. URL: http://zpu-journal.ru/e-zpu/2010/1/ Gopko/ [архивировано в WaybackMachine] (дата обращения: 18.02.2018).

Друкер, П. Ф. (2004) Энциклопедия менеджмента. М. ; СПб. ; Киев : Изд. дом «Вильямс». 422 с.

Дункан, У. Дж. (1996) Основополагающие идеи в менеджменте. Уроки основоположников менеджмента и управленческой практики. М. : Дело. 272 c.

Кастельс, М. (2000) Информационная эпоха: экономика, общество и культура / пер. с англ. под науч. ред. О. И. Шкаратана. М. : ГУ ВШЭ. 608 с.

Тейлор, Ф. У. (1991) Принципы научного менеджмента. М. : Контроллинг. 104 с.

Эмерсон, Г. (1992) Двенадцать принципов производительности. 2-е изд. М. : Экономика. 224 с.

Дата поступления: 20.02.2018 2.

Гопко Владимир Васильевич - кандидат философских наук, доцент кафедры экономики, менеджмента и маркетинга Омского государственного педагогического университета. Адрес: 644099, г. Омск, ул. Интернациональная, д. 6. Тел.: +7 (3812) 23-37-42. Эл. адрес: go.vladi@yandex.ru

Gopko Vladimir Vasilyevich, Candidate of Philosophy, Associate Professor, Department of Economics, Management and Marketing, Omsk State Pedagogical University. Postal address: 6 Internatsionalnaya St., 644099 Omsk, Russian Federation. Tel.: +7 (3812) 23-37-42. E-mail: go.vladi@yandex.ru

SPIN-код: 8661-6562

AuthorID: 300571

Для циитирования:

Гопко В. В. К вопросу о философии и практике менеджмента в сфере образования [Электронный ресурс] // Горизонты гуманитарного знания. 2018. № 1. C. 113-122. URL: http://journals.mosgu.ru/ggz/article/view/705 (дата обращения: дд.мм.гггг). DOI: 10.17805/ggz.2018.1.7 